\title{
ODONTESTHES MIRINENSIS, SP.N. UM NOVO PEIXE-REI (PISCES, ATHERINIDAE, ATHERINOPSINAE) PARA O EXTREMO SUL DO BRASIL
}

\author{
Marlise de Azevedo Bemvenuti ${ }^{1}$
}

\begin{abstract}
ODONTESTHES MIRINENSIS, SP.N. A NEW SILVERSIDE (PISCES, Atherinidae, Atherinopsinae) from Southern Brazil. Odontesthes mirinensis, a new species of silverside, is described in coastal lagoons system of Rio Grande do Sul, Brazil. The new species is distinguished from other Odontesthes species by short snout and having 24-29 gill rakers on the lower branch of the first branchial arch. Osteological features (bones of the skull, axial skeleton and girdles) are included and discussed. Meristic and morphometric variables were analyzed separately, through multivariate procedures. Principal Component Analysis show that Odontesthes mirinensis, sp.n. does not exhibit significant geographic variation on body shape. KEY WORDS. Pisces, Atherinidae, Odontesthes, new species, osteology.
\end{abstract}

As espécies de peixes-rei do gênero Odontesthes, Evermann \& Kendall, 1906), estão restritas ao extremo sul da América do Sul, em ambientes de água doce, estuário ou mar. Recentes estudos sobre os peixes-rei (BEMVEnuti 1993, 1995; DYER 1994), revelaram a presença de uma espécie nova na lagoas costeiras do extremo sul do Brasil.

No presente trabalho apresenta-se a descrição de Odontesthes mirinensis, sp.n., baseada principalmente, em espécimens provenientes da Lagoa Mirim (Rio Grande do Sul). A nova espécie tem sido considerada por diversos autores (DYER 1994; FIALHO \& VERANI 1994), como Odontesthes aff. perugiae, devido a grande semelhança em seus caracteres morfológicos e merísticos. Comparações osteológicas apresentadas por BEMVENUTI (no prelo) e outros trabalhos em progresso, permitiram incorporar dados à sua descrição quanto à morfologia interna, contribuíndo para o conhecimento dos caracteres de maior importância taxonômica, uma vez que externamente os peixes-rei são muito semelhantes.

\section{MATERIAL E MÉTODOS}

\section{Coleta dos dados}

As coletas foram feitas através de redes de emalhar (espera) ou arrastos de praia, nos seguintes locais: Lagoa dos Quadros, Lagoa Itapeva, Lagoa do Armazém, Lagoa Fortaleza ao norte do Estado; delta do Rio Guaíba, Porto Alegre; Lagoa dos Patos: Camaquã e Tapes ao norte e Canal São Gonçalo ao sul; Lagoa

1) Departamento de Oceanografia. Fundação Universidade de Rio Grande. Caixa Postal 474. 96201-900 Rio Grande, Rio Grande do Sul. Brasil. 
Mirim e Lagoa Mangueira (Fig. 1). Os exemplares foram depositados na coleção da Fundação Universidade de Rio Grande (FURG), Laboratório de Ictiologia e o holótipo no Museu de Ciências da PUC (MCP), Porto Alegre, RS. As medidas e contagens foram obtidas do lado esquerdo do peixe e estão detalhadas em BEMVENUTI (1995).

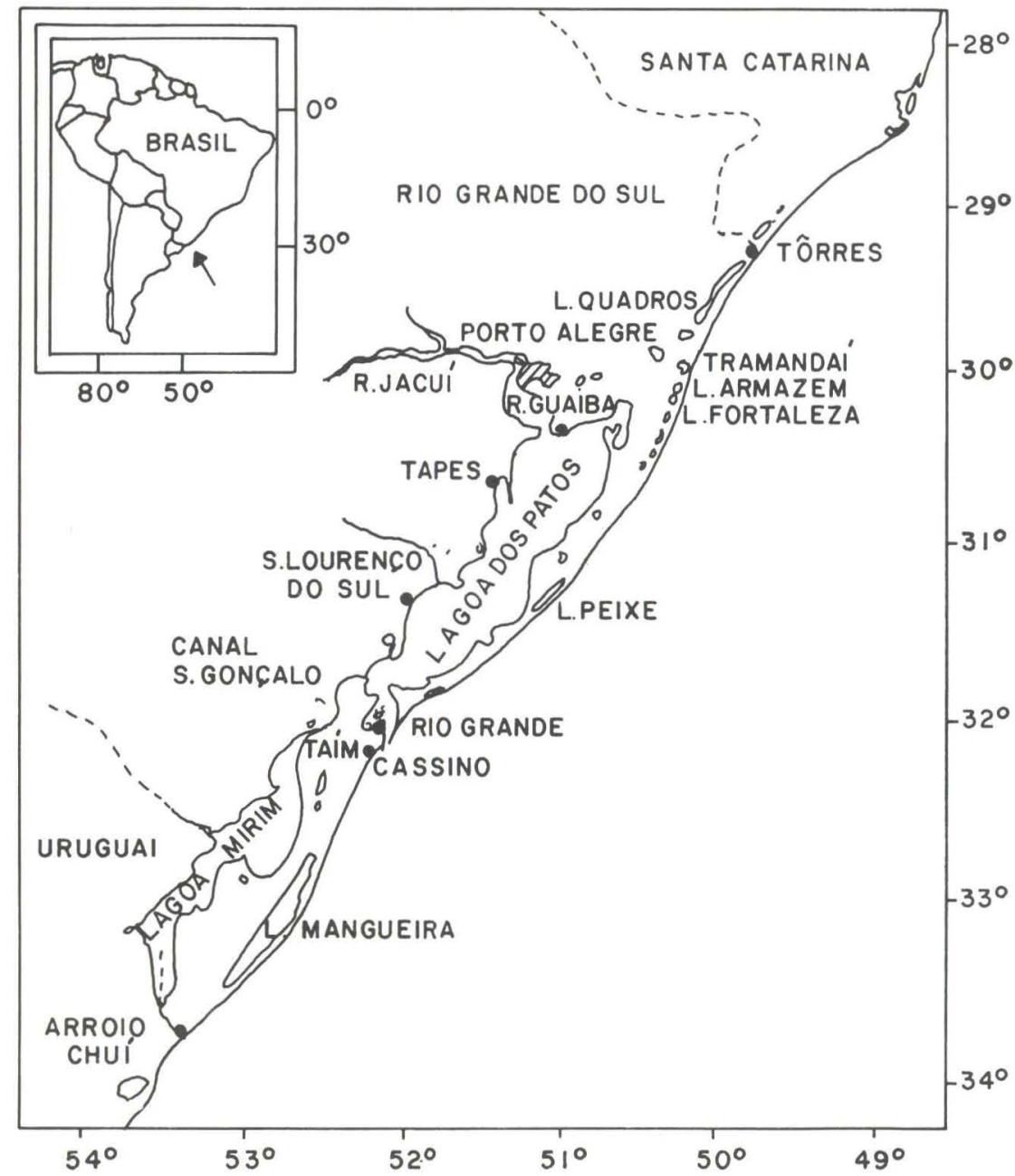

Fig. 1. Área de distribuição de Odontesthes mirinensis, sp.n. no extremo sul do Brasil.

Os caracteres morfométricos obtidos com precisão de $0,1 \mathrm{~mm}$ foram: comprimento padrão (cp); distância pré-dorsal 1 (pd1); distância pré-dorsal 2 (pd2); distância pré-anal (pan); distância pré-peitoral ( $\mathrm{pp} 1)$; distância pré-pélvica (pp2); comprimento da cabeça (cab); altura máxima da cabeça (altcab); focinho 
(foc); diâmetro horizontal do olho (olho); distância interorbital (intorb); largura da boca (boca); comprimento da maxila (max); altura mínima do pedúnculo caudal (altped); distância entre as origens da peitoral e pélvica (p1p2); distância entre a origem da peitoral e o pedúnculo caudal (p1 pc); distância entre a origem da pélvica e o pedúnculo caudal (p2pc); distância entre a origem da anal e o pedúnculo caudal (anpc); distância entre a origem da primeira dorsal e o pedúnculo caudal (d1pc); distância entre a origem da segunda dorsal e o pedúnculo caudal (d2pc); distância entre as origens das dorsais ( $11 \mathrm{~d} 2)$; distância entre as origens da anal e primeira dorsal (and1); distância entre as origens da anal e segunda dorsal (and2); distância entre as origens da anal e peitoral (anp1); distância entre as origens da anal e pélvica (anp2).

Os caracteres merísticos foram: número de espinhos e raios da nadadeira dorsal (d1, d2); número de raios da nadadeira anal (an); número de raios da nadadeira anal anteriores ao início da segunda dorsal (and2); número de raios da nadadeira peitoral (p1); número de escamas da linha longitudinal, contadas acima da faixa prateada (eslong); número de escamas anteriores a primeira dorsal (espd1); número de escamas ao redor do pedúnculo caudal (esped); número de rastros superiores do primeiro arco branquial (brqs); número de rastros inferiores do primeiro arco branquial, incluíndo o rastro do ângulo (brqi); número de rastros totais do primeiro arco branquial (brqt); número de vértebras (vert). Ao final são apresentadas tabelas com as proporções corporais médias, os caracteres merísticos médios, seus limites de amplitude, seguidos do desvio e coeficiente de variação (cv $=$ desvio/média*100).

\section{ANÁLISE OSTEOLÓGICA}

Foram selecionados dois exemplares pequenos e um grande. Os exemplares pequenos foram diafanizados através da técnica de TAYLOR (1967), modificada por PotThoff (1983), que consiste de várias etapas, entre as quais a digestão enzimática com tripsina e a coloração dos ossos com alizarina, sendo preservados em glicerina no final. Os esqueletos dos exemplares maiores foram obtidos pelo processo de cocção (limpeza com água fervente). Os peixes depois de evicerados foram rapidamente mergulhados na água fervendo para limpeza e retirada total da musculatura. Após limpos, foram clareados em uma solução de água oxigenada $\left(\mathrm{H}_{2} \mathrm{O}_{2}-3 \%\right)$ e hidróxido de potássio $(\mathrm{HOH}-2 \%)$ e preservados a sêco. As ilustrações foram preparadas usando-se câmara clara acoplada ao microscópio estereoscópio.

Lista de ossos e abreviações, utilizadas nas figuras:

\section{A) Crânio}

- Região Etmoidal: (ET) etmóide, (EL) etmóide lateral, (V) vômer, (N) nasal.

- Região Orbital: (IO) infra-orbitais, (F) frontal, (PAS) paraesfenóide, (BAS) basiesfenóide, (PTS) pteroesfenóide.

- Região Ótica: (P) parietal, (ES) esfenótico, (PTO) pterótico, (EPO) epiótico, (PRO) proótico. 
- Região Occipital: (EOC) exoccipital, (BOC) basioccipital, (SOC) supraoccipital.

- Região Mandibular: (PM) prémaxilar, (MX) maxilar, (AN) angular, (AR) articular, (D) dentário, (Q) quadrado, (HIO) hiomandibular, (MPT) metapterigóide, (ECT) ectopterigóide, (ENT) endopterigóide, (PL) palatino, (S) simplético.

- Série Opercular: (OP) opérculo, (POP) preopérculo, (IOP) interopérculo, (SOP) subopérculo.

\section{B) Esqueleto Axial}

- Coluna Vertebral: (VT) vértebras do tronco, (VC) vértebras caudais,

- Nadadeira Caudal: (u) uróstilo, (ep) epural, (hp) hipural, (php) parahipural, (un) uroneural.

\section{C) Esqueleto Apendicular}

- Cintura Peitoral: (ESC) escápula, (COR) coracóide, (Cl) cleitro, (SCL) supracleitro, (PT) postemporal.

- Cintura Pélvica: (BPT) basipterígio.

\section{MORFOMETRIA MULTIVARIADA}

Foram utilizados 25 caracteres morfométricos e nove merísticos, analisados separadamente (SEAL 1964; STRAuSS 1985; WinANS 1987). Foi empregada a análise dos componentes principais a partir da matriz de variância-covariância dos caracteres morfométricos log-transformados e da matriz de correlação dos caracteres merísticos transformados em raiz quadrada (SoKAL \& RohlF 1981). A transformação logarítmica dos caracteres morfométricos foi necessária para normalizar a distribuição dos dados, homogeneizar as variâncias (BOOKSTEIN et al. 1985), além de tornar a matriz de dispersão independente do escalonamento e preservar a alometria original (JOLICOEUR 1963). No modelo multivariado o primeiro componente $(\mathrm{CP} 1)$ expressa o fator tamanho e apresenta coeficientes positivos, semelhantes e proporcionais aos coeficientes alométricos dos caracteres em relação ao seu tamanho (BOOKSTEIN et al. 1985), sendo interpretado como um componente que representa o vetor tamanho. Os componentes subseqüentes são os indicadores de diferenças na forma dos organismos estudados (NEFF \& MARCUS 1980; REIS 1988), observado através de seus coeficientes positivos e negativos, cuja correlação é variada. Infelizmente medidas de forma não são sempre independentes do tamanho devido às relações alométricas (WINANS 1987). Alometria é um fenômeno constante no desenvolvimento ontogenético, que expressa o crescimento diferenciado de certas partes do corpo, verificado através das diferentes proporções corporais entre organismos relacionados. Os coeficientes alométricos foram calculados a partir da divisão de cada um deles, pela média dos mesmo no primeiro componente, podendo ser interpretados como coeficientes de crescimento relativo (RAUCHEMBERGER 1988; CAVALCANTI \& LOPES 1990). O processamento dos dados foi efetuado através do programa NTSYS-pc (RoLHF 1989) para microcomputadores. 


\section{RESULTADOS E DISCUSSÃO}

\section{Odontesthes mirinensis, sp.n.}

Fig. 2, Tabs I-III

Holótipo. BRasil, Rio Grande do Sul: Rio Grande (Lagoa Mirim, junto a sede da Estação Ecológica do Taím), MCP 17696, 109mm cp., 29 de dezembro de 1988; Angelo Maffisoni leg..

Parátipos FURG 88.002 (18) 105 à 140mm cp. Lagoa Mirim, E.E.Taím, Rio Grande, RS, Brasil 29 de dezembro de 1988.

Outros espécimens medidos. Brasil, Rio Grande do Sul: FURG 86.024 (28) Lagoa dos Quadros, Osório set 1986; FURG 87.017 (7) Lagoa Mirim, Rio Grande 18 jul 1987; FURG 87.042 (2) idem jul 1987; FURG 87.052 (1) Lagoa dos Patos, Butiá 15 dez 1987; FURG 87.053 (3) Lagoa dos Patos, Tapes 18 dez 1987; FURG 87.061 (4) Arroio del Rei, Lagoa Mirim 4 nov 1987; Furg 87.062 (1) Lagoa dos Patos, Tapes $14 \mathrm{dez}$ 1987; FURG 87.063 (25) Lagoa Mirim, Bosque 20 out 1987; FURG 87.064 (39) Lagoa Mirim, Taím 5 out 1987; FURG 88.005 (1) Lagoa dos Patos, entre Pelotas e Tapes 5 jun 1988; FURG 90.002 (11) Lagoa Mirim 2 mai 1990; FURG 92.002 (1) Lagoa Mangueira ago 1992; FURG 92.003 (1) idem 1 out 1992; FURG 92.004 (13) Canal São Gonçalo, Pelotas out 1992; FURG 92.008 (16) Lagoa Fortaleza, Cidreira, 15 jan 1992; FURG 93.001 (12) Canal São Gonçalo, Pelotas, fev 1993; FURG 93.002 (8) idem, mar 1993; MCP 10.573 (3) Rio Guaíba, Port Alegre 22 ago 1985; MCP 10.579 (2) Lagoa dos Patos, Camaquã 20 out 1985.

Diafanizados: FURG 87.002 ( $87 \mathrm{~mm} \mathrm{cp)} \mathrm{Lagoa} \mathrm{Mirim} 18$ jul 1987; FURG n.cat. (73mm cp) Taím, Lagoa Mirim 5 out 1987; esqueleto - FURG n.cat. (295mm cp) Lagoa Mirim 10 jun 1987.

Diagnose. Odontesthes mirinensis distingue-se das demais espécies capturadas no extremo sul do Brasil, pela presença de 31-37 rastros no primeiro arco branquial, com exceção de $O$. argentinensis (27-33) e $O$. perugiae (28-37). Difere destas espécies, porque possui 24-29 rastros no ramo inferior do primeiro arco branquial, enquanto $O$. argentinensis tem 20-24, e pelo focinho curto 6,1-7,9\% do $\mathrm{cp}$, ao invés de $8,2-10,7 \%$ em $O$. perugiae.

Descrição. O comprimento padrão dos exemplares examinados variou de 65,5-225mm. As relações morfométricas e merísticas do holótipo e demais exemplares examinados, encontram-se nas tabelas I e III.

Corpo alto, recoberto por escamas grandes ciclóides com bordo posterior irregular; três séries de escamas suboculares. Cabeça pequena, 20,5-24\% do comprimento padrão (cp); focinho curto $6,1-7,9 \%$ do $\mathrm{cp}$; distância interorbital (intorb) $24-32 \%$ do comprimento da cabeça, $24,6 \%$ nos peixes pequenos e $31-32 \%$ nos maiores; olhos grandes $22-29 \%$ do comprimento da cabeça, diminuindo nos adultos 18-19\%; boca protrátil; maxila e mandíbula em mesma projeção anterior; dentes mandibulares dispostos irregularmente em duas fileiras; vômer sem dentes; endopterigóides com placa de dentes. Segunda dorsal origina-se sobre a vertical que passa entre o nono e $11^{\circ}$ raios da nadadeira anal, terminando ambas na mesma vertical. Extremidade distal das nadadeiras peitorais, apoiadas à superfície do 

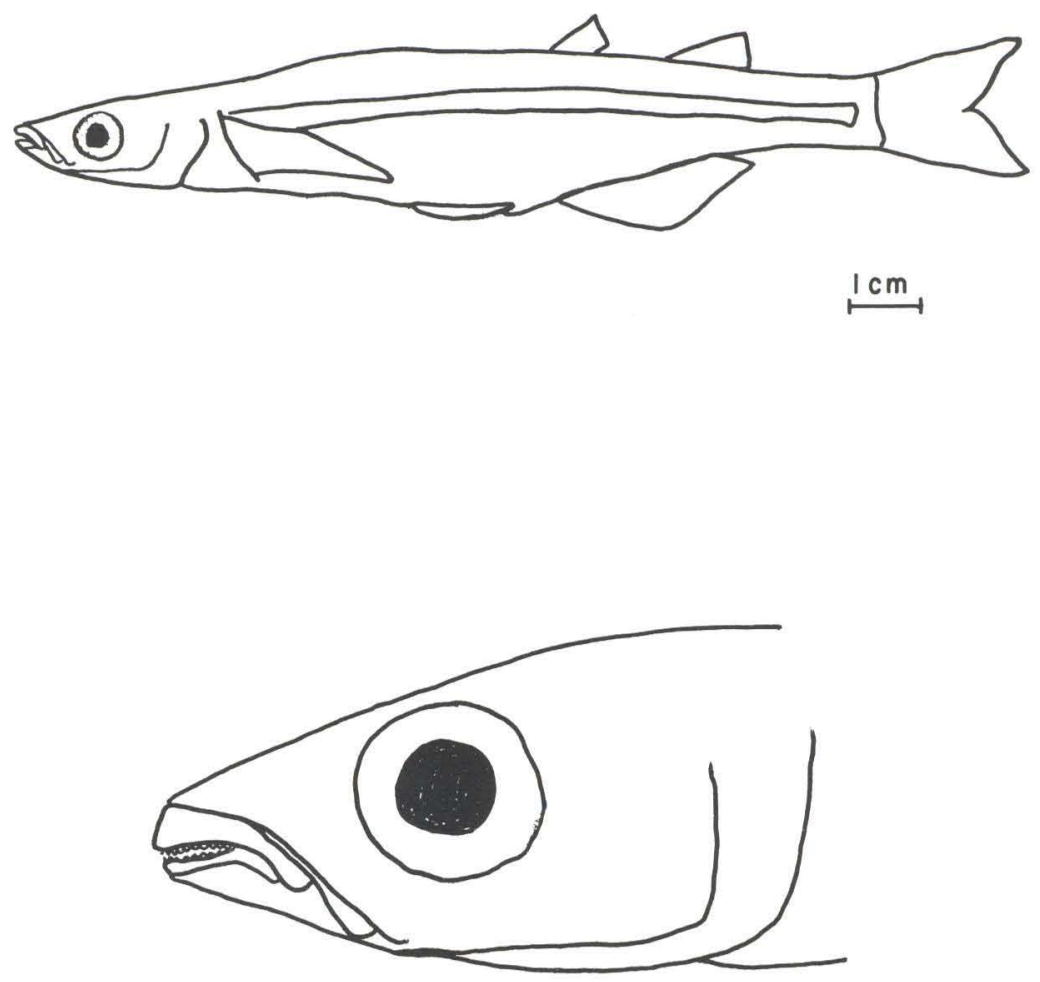

\section{$5 \mathrm{~mm}$}

Fig. 2. Odontesthes mirinensis, sp.n., 109mm comprimento padrão, MCP 17696 Lagoa Mirim, Estação Ecológica do Taím, Rio Grande (Rio Grande do Sul), 29 de dezembro de 1988 (A). Detalhe da cabeça e boca, vista lateral (B).

corpo, alcança a origem das nadadeiras pélvicas; origem das pélvicas distante da origem da anal, cerca de cinco a sete séries de escamas (cinco no holótipo); pélvicas muito juntas, alguns exemplares com membrana interpélvica. Segunda dorsal com 8-10 raios, anal com 14-18 raios, peitorais com 12-13 raios; linha longitudinal com 46-52 séries de escamas das quais 20-25 estão localizadas anteriormente à primeiro dorsal. Rastros do primeiro arco branquial finos, compridos 6-9 no ramo superior, 24-29 no inferior, totalizando 31-37 (holótipo: 7+26). Vértebras: 25 pré-caudais, 21-23 caudais, totalizando 46-48; as primeiras vértebras caudais (oito ou nove), possuem o arco hemal expandido formando um tubo hemal, por onde se prolonga a bexiga gasosa; as paredes dos arcos hemais são bastante alargadas mantendo-os próximos um do outro.

Etimologia. O nome mirinensis é derivado do nome geográfico, Lagoa Mirim, sua localidade-tipo, acrescido do sufixo latim ensis=origem. 
Tabela I. Dados morfométricos e merísticos de Odontesthes mirinensis, sp.n.. (cv) Coeficiente de variação.

\begin{tabular}{|c|c|c|c|c|c|c|c|}
\hline \multirow{2}{*}{ Variáveis } & \multirow{2}{*}{$\mathrm{n}$} & \multicolumn{2}{|c|}{ Limites } & \multirow{2}{*}{ Média } & \multirow{2}{*}{ Desvio padrão } & \multirow{2}{*}{$\begin{array}{l}\text { Coeficiente } \\
\text { de variação }\end{array}$} & \multirow{2}{*}{ Holótipo } \\
\hline & & Minimo & Máximo & & & & \\
\hline $\mathrm{cp}(\mathrm{mm}$ & 65,5 & 225.0 & & & & & 109 \\
\hline \multicolumn{8}{|c|}{ Percentagens do comprimento padrão } \\
\hline pd1 & 46 & 58,8 & 64,7 & 61,3 & 1,51 & 2,46 & 62,4 \\
\hline $\mathrm{pd} 2$ & 46 & 71,8 & 76,8 & 74,3 & 1,21 & 1,63 & 76,4 \\
\hline pan & 46 & 62,1 & 67,6 & 65.0 & 1,49 & 2,29 & 64,6 \\
\hline $\mathrm{pp} 1$ & 46 & 21,9 & 26,2 & 24.3 & 0.95 & 3,92 & 24,6 \\
\hline $\mathrm{pp} 2$ & 46 & 43,9 & 48,7 & 46,3 & 1,18 & 2,54 & 45,6 \\
\hline$c a b$ & 46 & 20,5 & 23,9 & 22,5 & 0,78 & 3,47 & 21,6 \\
\hline altcab & 46 & 11,3 & 14,3 & 12.5 & 0,75 & 5,97 & 12,7 \\
\hline foc & 45 & 6,1 & 7,9 & 6,9 & 0,38 & 5,44 & 7,0 \\
\hline altped & 46 & 6.6 & 9,6 & 8.1 & 0,55 & 6,78 & 8.5 \\
\hline p1p2 & 46 & 21,3 & 26.5 & 24,3 & 1,12 & 4.61 & 23,3 \\
\hline $\mathrm{p} 1 \mathrm{pc}$ & 46 & 75,5 & 79,0 & 77,1 & 0,92 & 1,19 & 76,1 \\
\hline $\mathrm{p} 2 \mathrm{pc}$ & 46 & 55,5 & 60,1 & 57.3 & 1,29 & 2,24 & 56.4 \\
\hline $\operatorname{anpc}$ & 46 & 35,8 & 41,5 & 38,1 & 1,19 & 3,13 & 37,6 \\
\hline $\mathrm{d} 1 \mathrm{pc}$ & 46 & 36,3 & 41,9 & 39,4 & 1,15 & 2,92 & 39,4 \\
\hline $\mathrm{d} 2 \mathrm{pc}$ & 46 & 24,2 & 29.6 & 26,9 & 1.15 & 4,28 & 26,0 \\
\hline $\mathrm{d} 1 \mathrm{~d} 2$ & 46 & 11,1 & 15.8 & 13,2 & 1.07 & 8,09 & 13,4 \\
\hline and 1 & 46 & 16,5 & 20,1 & 18,3 & 0,96 & 5,27 & 19,6 \\
\hline and 2 & 46 & 18,9 & 22,8 & 20,7 & 0,99 & 4,79 & 20,9 \\
\hline anp 1 & 46 & 39,2 & 44,4 & 42,4 & 1,31 & 3.09 & 41.0 \\
\hline anp 2 & 46 & 17.0 & 22,3 & 19,9 & 1,30 & 6,53 & 18,7 \\
\hline \multicolumn{8}{|c|}{ Percentagens do comprimento da cabeça } \\
\hline foc & 45 & 28,1 & 33,3 & 30,7 & 1,40 & 4,57 & 29.7 \\
\hline olho & 46 & 18,0 & 29,2 & 25,6 & 2,84 & 11,10 & 27,9 \\
\hline intorb & 46 & 24,3 & 32.0 & 28.1 & 1.78 & 6,32 & 29.7 \\
\hline boca & 46 & 22,8 & 30,0 & 25.7 & 1,93 & 7,54 & 23,3 \\
\hline $\max$ & 46 & 29,6 & 35,9 & 33,2 & 1,66 & 5,01 & 33,9 \\
\hline \multicolumn{8}{|c|}{ Contagens } \\
\hline d1 & 37 & 3 & 6 & 4,3 & 0,74 & 17.05 & 5,0 \\
\hline $\mathrm{d} 2$ & 38 & 8 & 10 & 8,6 & 0.55 & 6,40 & 8.0 \\
\hline an & 38 & 14 & 18 & 15.9 & 0.82 & 5,16 & 17.0 \\
\hline and 2 & 36 & 9 & 11 & 9.8 & 0,67 & 6,87 & 10,0 \\
\hline p1 & 21 & 12 & 13 & 12,8 & 0,43 & 3,34 & 12,0 \\
\hline eslong & 37 & 46 & 52 & 49,2 & 1,60 & 3,24 & 50.0 \\
\hline espd1 & 36 & 20 & 25 & 21,7 & 1,22 & 5,63 & 21,0 \\
\hline esped & 38 & 14 & 16 & 14,6 & 0,93 & 6,35 & 16.0 \\
\hline brqs & 37 & 6 & 9 & 7,4 & 0,75 & 10,15 & 7.0 \\
\hline brai & 37 & 24 & 29 & 26,7 & 1,64 & 6,17 & 26,0 \\
\hline brat & 37 & 31 & 37 & 34,1 & 1,90 & 5,59 & 33,0 \\
\hline
\end{tabular}

Distribuição Geográfica. Odontesthes mirinensis foi coletada desde a Lagoa dos Quadros (ao norte do Estado) até as lagoas Mirim e Mangueira (ao sul), incluíndo as lagoas menores de Cerquinha, Fortaleza e outras (a leste). Na Lagoa dos Patos a espécie foi obtida junto a cidades de Tapes, Camaquã e também ao norte, no Rio Guaíba. Sua maior abundância foi registrada na Lagoa Mirim com muitos indivíduos juvenis, atingindo a área do Canal São Gonçalo, Pelotas (Fig. 1). 


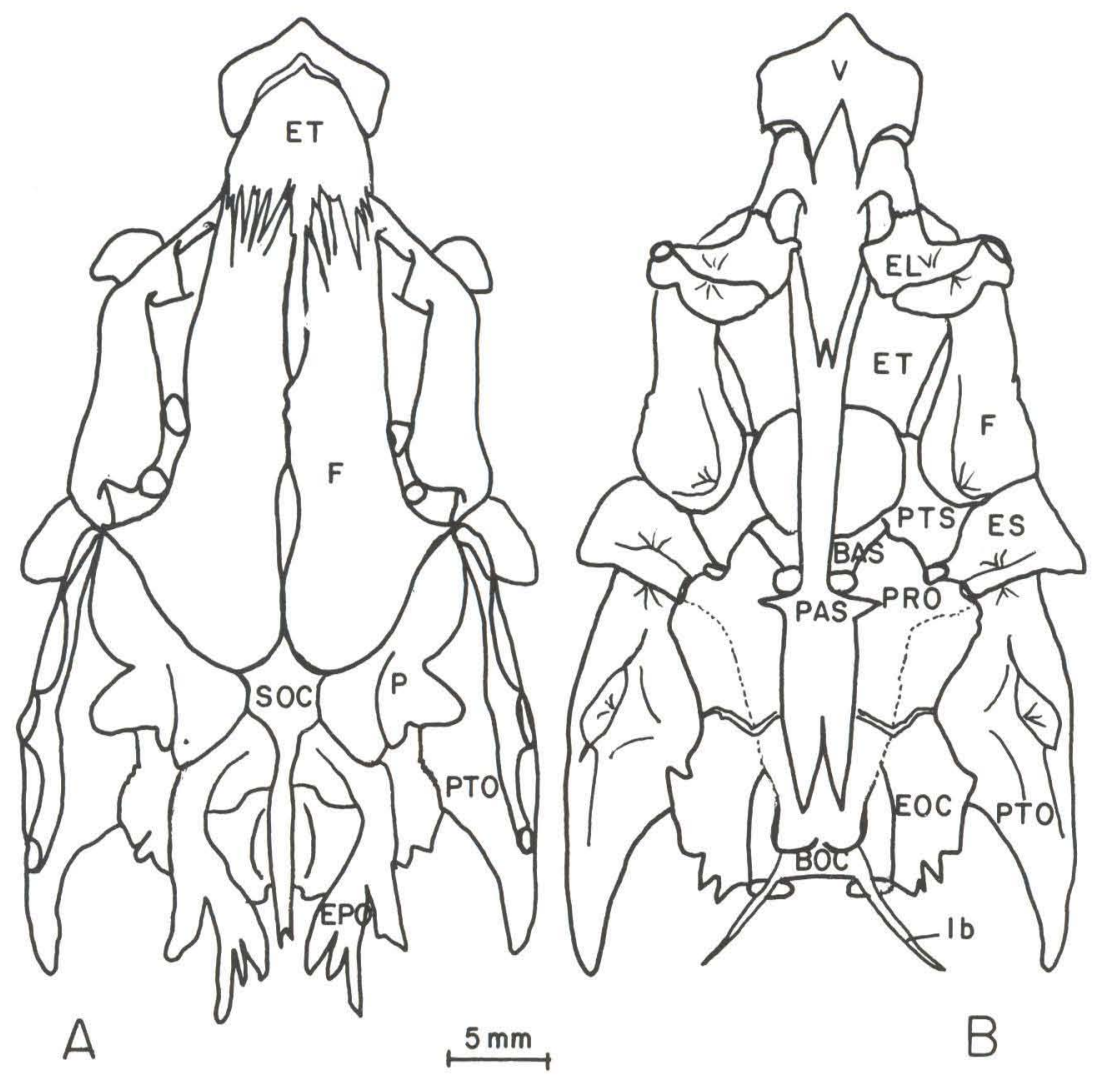

Fig. 3. Odontesthes mirinensis sp.n. Neurocrânio em vista dorsal $(A)$ e ventral $(B) ; \quad l b=$ ligamento de Baudelot.

\section{ANÁLISE OSTEOLÓGICA}

A) CRÂNIO

É formado pelo neurocrânio e branquiocrânio.

\section{- NEUROCRÂNIO}

Ou crânio propriamente dito, é constituído por ossos frágeis e transparentes (Fig. 3). Em vista dorsal tem a forma retangular. Sua projeção anterior forma o rostro do peixe. A morfologia do crânio é similar às demais espécies do gênero Odontesthes (BEMVENUTI 1995).

\section{Região Etmoidal.}

O etmóide (ET) é um osso ímpar de origem pericondral, mantem-se cartilaginoso durante o estágio adulto de alguns peixes (RoJo 1991), inclusive em alguns aterinídeos (CHERNOFF 1986). A ausência de mesetmóide em Odontesthes 
foi registrada por WHITE (1985) que a considerou como um caráter derivado. Em Odontesthes mirinensis o etmóide tem a forma arredondada anteriormente, ocupando quase a metade do teto interno do crânio. Articula-se ventralmente, com o vômer e lateralmente com os etmóides laterais, estando os frontais, situados dorsalmente. Os etmóides laterais (EL) estão situados em posição anterior à órbita, formando as paredes mediano-laterais do etmóide e articulando-se anteriormente com o vômer. Em posição ventral tem a forma arredondada, com uma projeção postero-dorsal mais alongada. Cada osso possui uma projeção lateral interna que se apoia sobre o paraesfenóide em maior ou menor extensão e outra externa que dá suporte ao primeiro infra-orbital (IO1).

$\mathrm{O}$ vômer $(\mathrm{V})$ é um osso ímpar de posição antero-ventral, que forma o teto do palato. É coberto dorsalmente pelo etmóide, localizando-se entre os etmóides laterais. Articula-se firmemente com o paraesfenóide em posição postero-ventral. $\mathrm{Na}$ extremidade anterior possui projeções laterais bem desenvolvidas na forma de uma meia-lua. O rostro do peixe é formado por um processo mediano largo. A presença de dentes, variável nas demais espécies do gênero, está ausente em Odontesthes mirinensis.

Os nasais $(\mathrm{N})$ tem o bordo interno em forma de um tubo completo, por onde passa parte do canal sensorial supra-orbital (RoJo 1991). Localizam-se dorsalmente sobre a região etmoidal. Anteriormente ligam-se aos infra-orbitais através de uma projeção ventral, característica da subfamília Atherinopsinae (WhiTE 1985) (Fig. 4).

\section{Região Orbital.}

Os infra-orbitais (IO) são uma série de ossos dérmicos inferiores ao bordo do olho, geralmente associados ao canal sensorial infra-orbital. RosEN (1964) descreveu a ausência do terceiro, quarto e quinto ossos. Segundo o autor a perda de alguns infra-orbitais pode ser uma característica secundária, pois está relacionada com o tamanho do olho, relativamente maior nos aterinídeos. CHERNOFF (1986) relacionou os peixes-rei do Velho Mundo como tendo três ossos infraorbitais anteriores, com poucas exceções e os do Novo Mundo com dois ossos anteriores. Segundo Rojo (1991) a série inicia com o lacrimal (IO1) e termina com o dermoesfenótico (IO6). Odontesthes mirinensis apresenta três ossos infraorbitais, com canais sensoriais alojados em túbulos principais e acessórios com seus respectivos poros, sendo os dois primeiros, anteriores à orbita (Fig. 4). O infra-orbital 1 (IO1) é também chamado antorbital, devido a sua posição frontal ao olho (antero-superior à órbita). Por apresentar o canal sensorial infra-orbital, foi considerado como IO1. O infra-orbital 1 (IO1) possui um canal sensorial principal e outro perpendicular a ele com três poros. Um canal acessório, independente do principal, apresenta quatro pequenos poros na extremidade posterior. O infra-orbital 2 (IO2) é também chamado lacrimal, situa-se abaixo da órbita e articula-se anteriormente com o IO1. Tem a forma triangular com um canal principal dorsal e três canais acessórios longos com cinco poros. O terceiro, considerado como IO6, tem posição pós-orbital e geralmente permanece ligado ao crânio dorsalmente, sendo por isso denominado dermoesfenótico. Possui um canal 
principal de posição dorso-ventral, que se comunica com um pequeno canal acessório superior. A borda posterior, estreita estende-se no comprimento do osso.

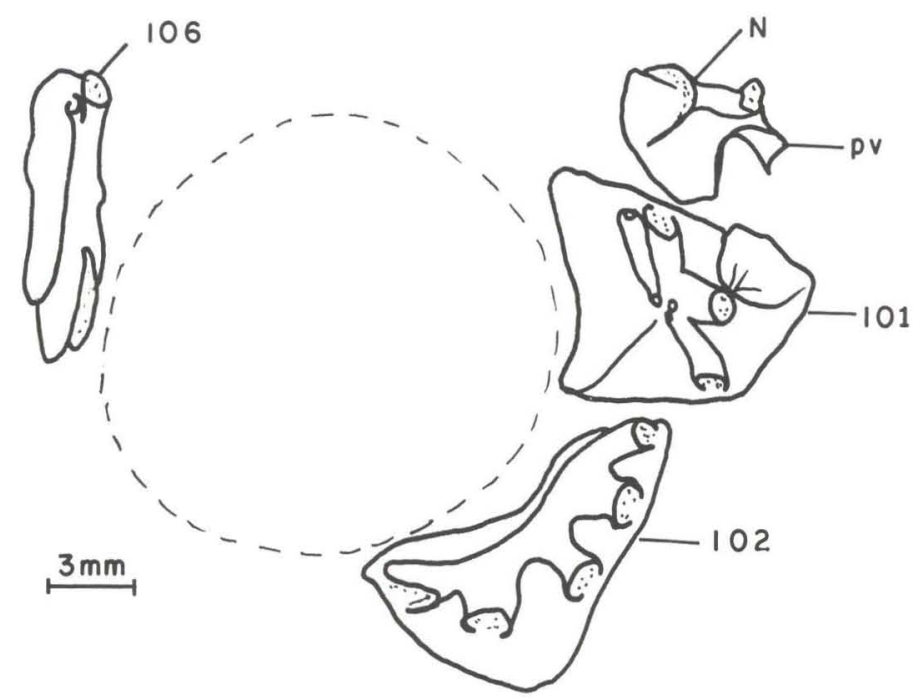

Fig. 4. Série infra-orbital, vista lateral externa desenhado do lado direito. (pv) Processo ventral, (N) nasal; (IO1) primeiro infra-orbital, (IO2) segundo infra-orbital (lacrimal), (IO6) sexto infra-orbital (dermoesfenótico).

Os frontais (F) são ossos largos, de origem dermal, que ocupam grande área dorsal do crânio, cobrindo externamente a órbita. Apresentam bordas parcialmente separadas por uma fontanela craniana, cujo contato se dá apenas na região mediana. Em sua superfície dorsal encontra-se o canal sensorial supraorbital, de forma curva para os lados, com cinco poros (Fig. 3), característica dos Atherinopsinae (WHITE 1985). Os frontais conectam-se posteriormente com o supraoccipital, cobrindo-o parcialmente. Em posição postero-lateral estão os esfenóticos e parietais. Os frontais estão posicionados posteriormente ao etmóide e etmóides laterais.

O paraesfenóide (PAS) é um osso ímpar que forma a maior parte da base do crânio. É um osso longo de posição ventral conectado entre o vômer e o basioccipital. Sua união com o vômer, anteriormente, tem a forma de um "V". Posteriormente, a extremidade distal bifurca-se em dois prolongamentos que vão além da metade do basioccipital. Em sua posição mediana apresenta uma estrutura em forma de asas laterais. O basiesfenóide (BAS) é um osso ímpar em forma de "Y", conectado dorsalmente aos proóticos e pteroesfenóides. Ventralmente estende-se em direção ao paraesfenóide com o qual se conecta através de expansões ósseas. Os pteroesfenóides (PTS) são pareados, de origem endocondral e localizados ventralmente, junto ao basiesfenóide (impar). Comunicam-se anteriormente com os frontais e posteriormente com os esfenóticos e proóticos. Nomes antigos como alisfenóides e pleuroesfenóides (utilizados em mamíferos e répteis, respecti- 
vamente), não devem ser usados porque não são homólogos aos pteroesfenóides dos peixes (ROJO 1991). Os três últimos ossos PAS, BAS, PTS apresentam formas semelhantes na maioria das espécies de Odontesthes, estudadas por BEMVENUTI (1995).

\section{Região Ótica.}

Os parietais (P) são ossos dérmicos de forma laminar plana, que cobrem a região ótica dos peixes-rei. Limitam-se anteriormente com os frontais, lateralmente com os esfenóticos e posteriormente com os pteróticos. O supraoccipital estende-se entre eles separando-os um de cada lado do crânio.

Os esfenóticos (ES) são ossos pareados situados entre os frontais e os pteróticos (PTO). Estes últimos tem sobre seu lado dorsal externo, a continuação do canal sensorial supra-orbital, iniciado no frontal. Três poros ocorrem na porção do pterótico, resultando um total de sete poros no canal supra-orbital (Fig. 3). Possui uma depressão ventral onde se articula um dos côndilos do hiomandibular. Os epióticos (EPO) são ossos irregulares, que protegem a cápsula ótica dorsalmente. Estão circundados pelo supraocipital, parietais, pteróticos e exoccipitais. Sobre êles apoia-se firmemente a porção anterior do processo superior dos postemporais. Os proóticos (PRO) são ossos que protegem a cápsula ótica ventralmente. São irregulares encontrando-se ao longo da linha mediana ventral do crânio. O foramen trigeminofacial cruza o proótico por entre suas asas laterais junto ao esfenótico (Fig. 3).

\section{Região Occipital.}

Os exoccipitais (EOC) apresentam côndilos de articulação conectando o crânio à primeiro vértebra. Cada exoccipital faz contato por sutura com o basioccipital ventralmente, com os proóticos mais anteriormente e com o supraoccipital e epióticos dorsalmente.

O basioccipital (BOC) é um osso ímpar, que forma a parte posterior da base do crânio. Ventralmente localiza-se entre os dois exoccipitais e proóticos. Tem a forma de um " $\mathrm{U}$ " invertido, com abas laterais que se expandem até encontrarem o paraesfenóide anteriormente, com o qual se conecta. Posteriormente, as abas se fusionam formando uma base circular côncava que faz a articulação com o centro da primeira vértebra. Essas abas laterais do basioccipital são esculpidas por uma série de pequenos e irregulares sulcos ou fenestras, característica dos peixes-rei Atherinopsinae sul-americanos, dentre êles o gênero Odontesthes (WHITE 1985). O basioccipital também apresenta uma estrutura em suas laterais, em forma de espinhos finos, na direção postero-ventral, chamada "ligamento de Baudelot". É uma estrutura de ligação na base do crânio, ossificada apenas nos Atherinopsinae (WHITE 1985) (Fig. 3).

O supraoccipital (SOC) é um osso ímpar situado na linha mediana da regiāo postero-dorsal do crânio. Este osso conecta-se anteriormente com o frontal. lateralmente com o parietal e epiótico e postero-ventralmente com o exoccipital. Apresenta uma crista occipital desenvolvida com bordos sinuosos que se projeta além do extremo posterior do côndilo occipital. 


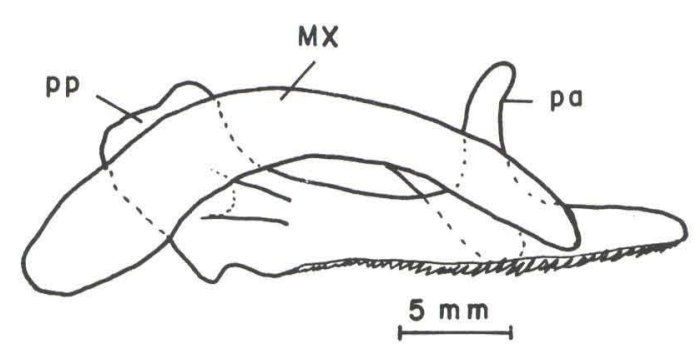

A

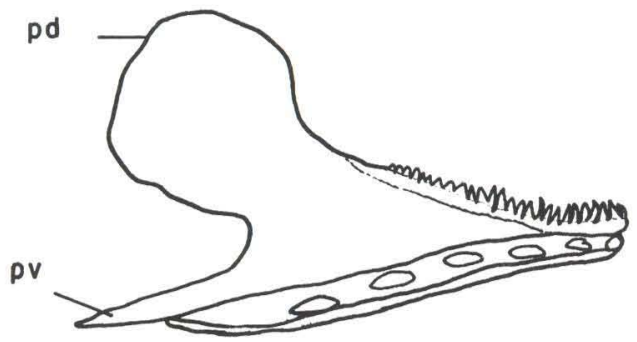

Fig. 5. (A) Prémaxilar e (B) dentário, vista lateral do lado direito. (MX) Maxilar, (pa) processo ascendente, (pp) processo posterior, (pd) processo dorsal, (pv) processo ventral.

\section{-BRANQUIOCRÂNIO}

\section{Região Mandibular.}

O prémaxilar (PM) está situado na margem anterior da mandíbula superior. É um osso curvo que possui dois processos: o ascendente (pa) que resulta na protratibilidade da boca (ROSEN 1964; ALEXANDER 1967) e o processo posterior (pp) de localização pós-maxilar (Fig. 5). O processo ascendente é fino, comprido, reto e dirigido para frente. É o local de encaixe do maxilar, que gira como um eixo, quando faz a protusão da boca. O processo posterior é mais alto do que nas demais espécies de Odontesthes. O prémaxilar tem maior comprimento quando relacionado à altura do processo posterior. Na porção inferior do prémaxilar estão várias fileiras de dentes curtos inseridos desordenadamente e dirigidos para trás. O maxilar (MX) forma as margens laterais da boca. É um osso achatado e retorcido ao longo de seu comprimento. A forma côncava do maxilar na extremidade dorsal, é evidente nas espécies com prémaxilar protrátil (ROSEN 1964). A porção anterior é separada em duas partes e está assentada sobre o processo ascendente do prémaxilar. A porção posterior descansa sobre a superfície externa do mesmo osso.

O dentário (D) apresenta uma estrutura tubular que aloja, na região ventral, o canal sensorial mandibular. Este tubo ósseo é formado por sete poros (Fig. 5). $\mathrm{Na}$ margem anterior desenvolvem-se várias fileiras de dentes. A extremidade posterior apresenta dois processos: um dorsal, grande e arredondado (pd), também chamado processo coronóide e outro ventral (pv) que se prolonga em ponta fazendo 
o encaixe com o processo anterior do angular, ligados através da cartilagem de Meckel. No ângulo posterior do angular há um processo ascendente superior variável em tamanho e uma concavidade onde se encaixa o côndilo do quadrado (Q). Esse osso tem a forma triangular, com um grande processo dirigido para trás, cobrindo parte do simplético (Fig. 6).

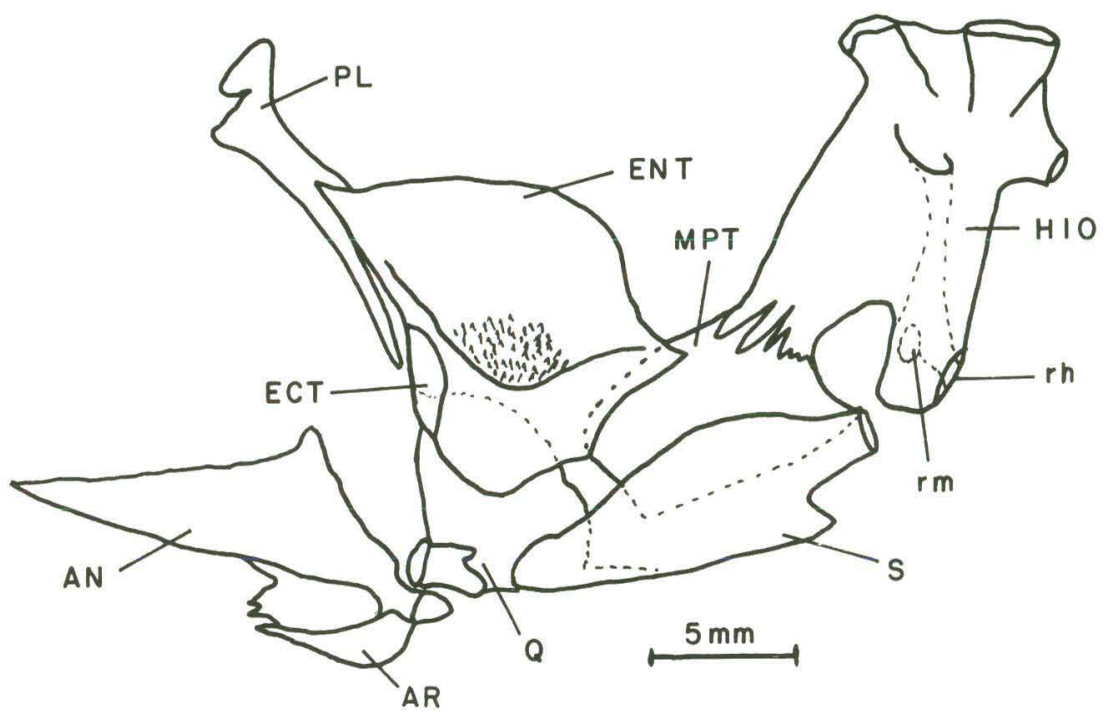

Fig. 6. Suspensório da mandíbula, vista lateral interna do lado direito. (HIO) Hiomandibular, (ENT) endopterigóide, (MPT) metapterigóide, (ECT) ectopterigóide, (PL) palatino, (AR) articular, (AN) angular, (Q) quadrado, (S) simplético, ( $\mathrm{rm}$ ) ramificação mandibular, (rh) ramificação hióidea.

O hiomandibular (HIO) é um elemento esqueletal de grande importância filogenética devido a sua antiguidade, uma vez que tem sido encontrado nos mais primitivos peixes já atuando como suporte para as mandíbulas (RoJo 1991). Na parte dorsal do hiomandibular estão três côndilos que se articulam anteriormente com a área escavada do esfenótico e pterótico e posteriormente com osso do opérculo. A parte ventral do hiomandibular liga-se ao metapterigóide (MPT) e simplético (S) (Fig. 6). Na face interna há um foramem superior que permite a passagem da ramificação hiomandibular do nervo facial (VII). O canal que se forma passa de um lado a outro do hiomandibular, dividindo-se em ramificação mandibular (rm) e hióidea (rh), na forma de dois outros foramens ventrais. A primeira ramificação abre-se ao exterior através de um poro na face externa do hiomandibular e a segunda é visível pela face interna do osso, em posição bem lateral. O orifício do canal mandibular está em posição elevada, apresentando um diâmetro pequeno. O endopterigóide (ENT) é um osso fino de grande tamanho, estendendo-se na base da órbita e que apresenta uma placa de dentes, particu- 
larmente numerosa em Odontesthes mirinensis, enquanto nas demais espécies o número de dentes é variável ou ausente (BEMVENUTI 1995). A borda posterior do endopterigóide une-se por sutura ao metapterigóide (MPT) e sua borda inferior curva conecta-se anteriormente com o ectopterigóide (ECT - muito pequeno), palatino (PL) e quadrado (Q) (Fig. 6).

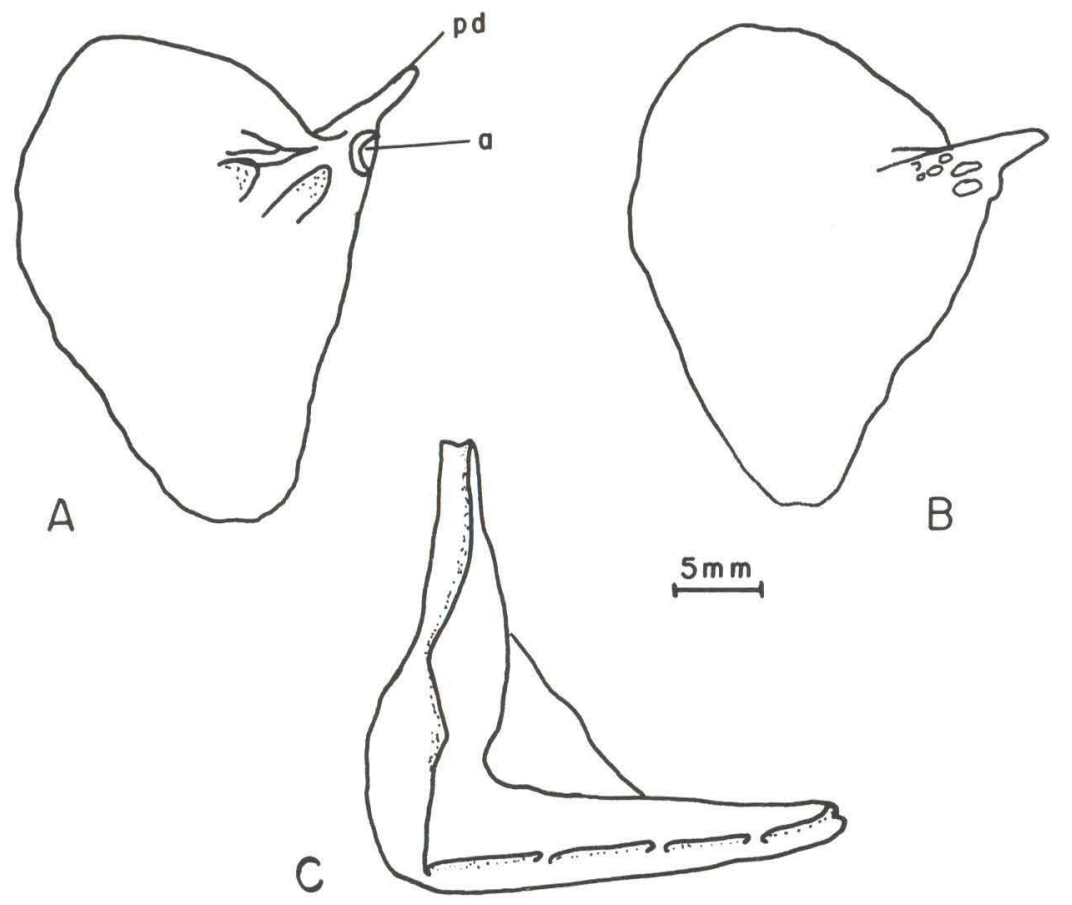

Fig. 7. Opérculo. (A) Vista interna do lado esquerdo; (B) vista externa do lado direito; (C) preopérculo vista lateral externa do lado direito. (pd) Processo dorsal, (a) ligação com o hiomandibular.

\section{Série Opercular.}

O opérculo (OP) é um osso largo, achatado e levemente triangular. No ângulo antero-dorsal há uma ossificação chamada processo dorsal (pd) e uma concavidade (a) que faz a articulação com o hiomandibular. Na face interna do opérculo há uma estrutura complexa, repleta de pontes ósseas e de foramens (orifícios) de tamanhos variados. Esses foramens são observados em ambas as faces do opérculo, sendo vários os orifícios externos (Fig. 7). O preopérculo (POP) tem a forma de um "L". A porção superior está conectada ao hiomandibular e a inferior ao quadrado. Sobrepõe-se externamente ao opérculo (OP), subopérculo (SOP) e interopérculo (IOP). Possui uma estrutura tubular parcialmente ossificada que percorre o osso em ângulo reto, alojando o canal sensorial. No ângulo do preopérculo o tubo se fecha completamente. A ramificação vertical-dorsal apre- 
senta-se totalmente aberta, enquanto nas demais espécies essa estrutura tubular apresenta duas aberturas (BEMVENUTI 1995). A ramificação ventral do túbulo apresenta quatro poros largos, número variável nas demais espécies do gênero. Nos peixes-rei do Velho Mundo este canal é relativamente pouco ossificado parecendo um canal aberto (CHERNOFF 1986).

\section{B) ESQUeleto AXIAL}

Os primeiros espinhos neurais da coluna vertebral (segunda à oitava vértebras) são curtos, comprimidos e alargados lateralmente, formando uma sólida lâmina vertical, que dá sustentação à cabeça do peixe (Fig. 8). O número de vértebras varia entre 46 e 48, como nas demais espécies de Odontesthes (BEMVENUTI 1995). A coluna vertebral é formada por 25 vértebras pré-caudais e 21-23 caudais. As primeiras vértebras caudais apresentam uma expansão do arco hemal formando um funil hemal, chamado urosoma, por onde se prolonga a bexiga gasosa. Esse funil hemal apresenta paredes alargadas de maneira que os arcos hemais ficam próximos uns dos outros. Suas paredes são constituídas de ossos finos, que ao se soldarem deixam numerosos orifícios nas suas laterais (Fig. 8). Essa modificação do arco hemal é característica dos peixes-rei da América do Sul, contrastando com aqueles da América do Norte, cujo funil hemal se desenvolve a partir da bifurcação do espinho hemal (WHITE 1985). Em Odontesthes mirinensis as três primeiras vértebras do funil hemal, possuem um espinho bem desenvolvido formando uma estrutura diferenciada do arco hemal.

A nadadeira caudal é formada por quatro hipurais ( $h p)$, três superiores à linha média do corpo e um inferior, todos ligados ao centro da vértebra terminal. O prolongamento inferior dessa vértebra, chamado parahipural (php), é alargado na base, estreitando-se para a extremidade. Junto a região anterior do parahipural há um processo lateral em forma de gancho retorcido chamado de hipurapófise (NURSALL 1963), que cobre a base do quarto hipural, servindo para prender parte do músculo caudal (ROJO 1991; NurSAll 1963). Os peixes-rei possuem apenas um uroneural parcialmente fusionado à placa hipural superior. Os dois epurais existentes representam vestígios da ossificação do espinho neural, ausente na última vértebra (ROSEN 1964). O final da última vértebra modificada, chamado uróstilo, tem uma projeção posterior afilada e comprida (Fig. 8).

\section{C) ESQUeleto APENDicular}

A superfície anterior do cleitro (CL) apresenta-se relativamente larga, com borda lateral convexa. A escápula (ESC) e o coracóide (COR) formam a parte postero-dorsal da cintura peitoral na qual o cleitro atua como suporte. Estão unidos por uma sutura óssea reta, tendo um aspecto denteado no centro da sutura (Fig. 9). Os postemporais (PT) constituem parte da cintura peitoral. Através de seu contato com o supracleitro (SCL), conectam a cintura peitoral à parte posterior do crânio. Possuem duas ossificações anteriores que fazem a conecção com o epiótico (EPO) dorsalmente e com o exoccipital (EOC) ventralmente. Entre elas há um pequeno processo semelhante a um espinho de pequeno tamanho. De acordo com CHERNOFF (1986), esse processo anterior somente ocorre nos peixes-rei do Novo Mundo. 

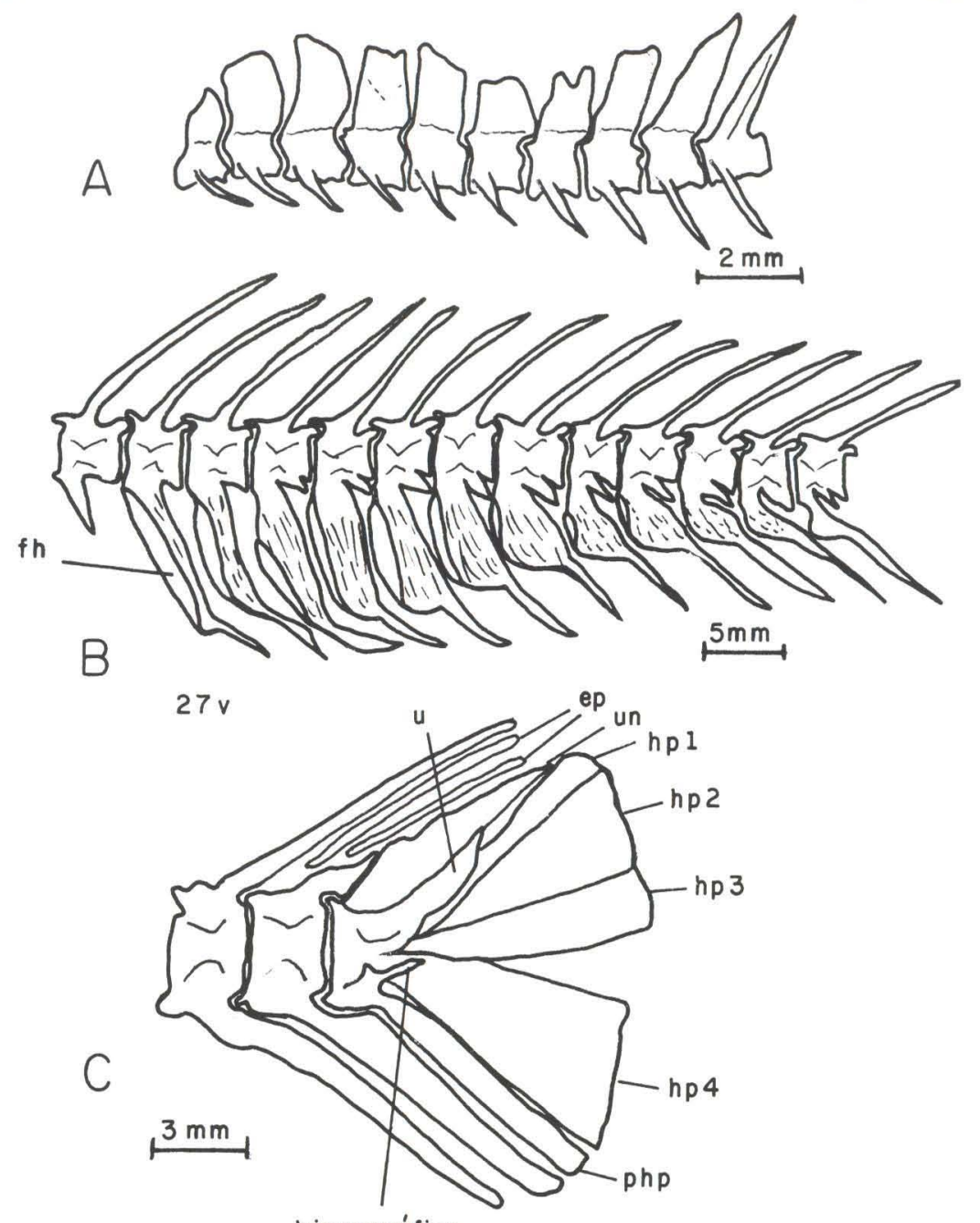

hipurapófise

Fig. 8. Coluna vertebral. (A) Vista lateral das primeiras vértebras pré-caudais; (B) primeiras vértebras caudais; (C) nadadeira caudal. (fh) Funil hemal, (ep) epurais, (un) uroneural, (hp1-hp4) hipurais, (php) parahipural; (u) uróstilo.

As nadadeiras pélvicas são sustentadas internamente por dois basipterígios (BPT) articulados entre si na porção anterior mediana. Apresentam forma triangular e alguns processos bem desenvolvidos (Fig. 10). O processo anterior (pa) mostra-se bem afilado, com uma placa interna que não alcança o final do osso pélvico. A redução dessa placa mediana foi estabelecida por CHERnOFf (1986) como um caráter derivado para os peixes-rei do Novo Mundo. O processo posterior interno (ppi) tem uma curvatura anterior curta e uma projeção posterior alongada. O processo posterior externo (ppe) termina em uma ponta muito comprida. 

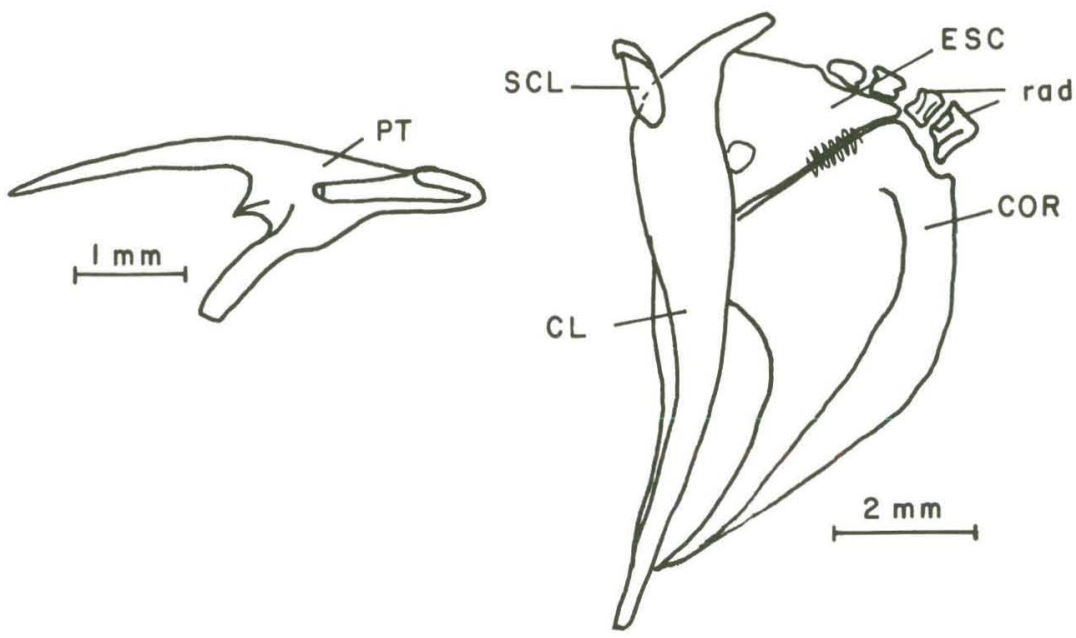

Fig. 9. Cintura peitoral, vista lateral externa do lado esquerdo. (ESC) Escápula, (COR) coracóide, (CL) cleitro, (SCL) supracleitro, (PT) postemporal, (rad) radiais.

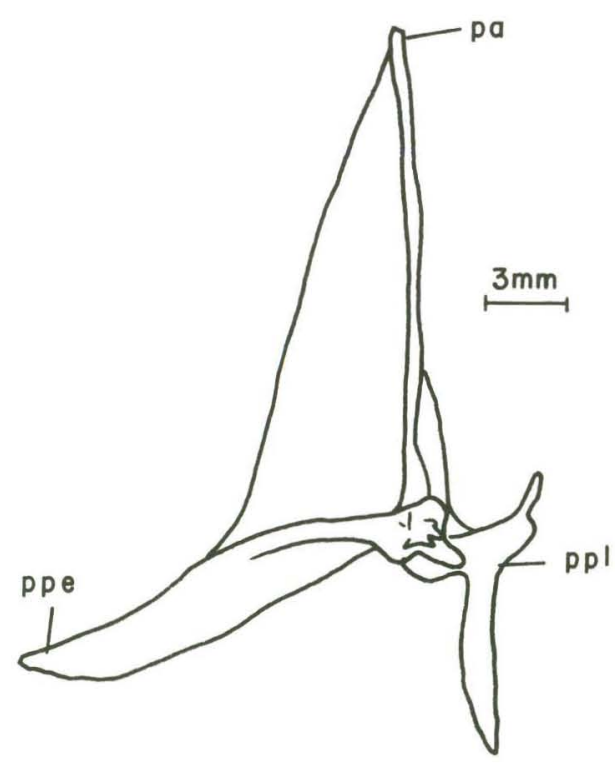

Fig. 10. Cintura pélvica-basipterígio, vista ventral do lado esquerdo. (pa) Processo anterior, (ppe) processo posterior externo, (ppi) processo posterior interno. 


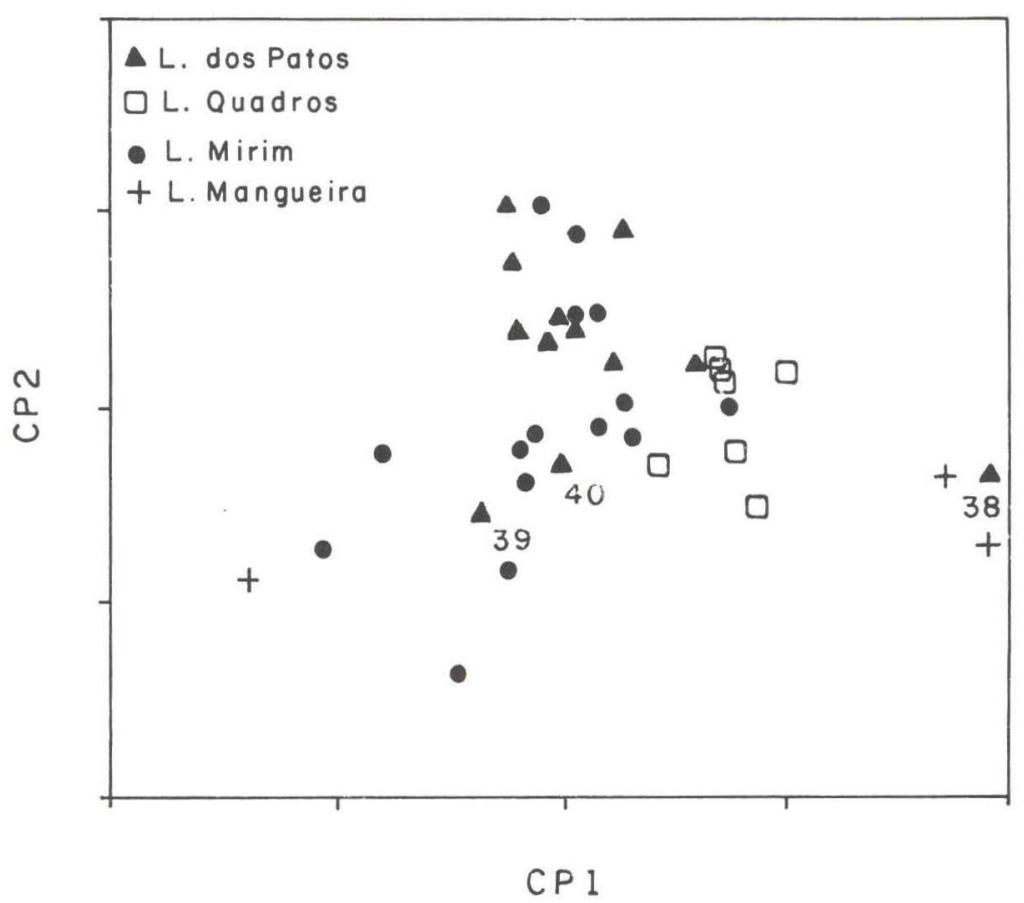

Fig. 11. Análise dos componentes princiais das 46 OTUs combinadas de Odontesthes mirinensis, sp.n.; projeção dos escores individuais no espaço dos dois primeiros componentes (CP1, CP2), para 25 caracteres morfométricos.

\section{VARIAC̣ÃO INTRAESPECÍFICA}

Odontesthes mirinensis apresentou um padrão homogêneo quanto a distribuição geográfica, daqueles peixes coletados na Lagoa Mirim, Lagoa dos Quadros e Lagoa dos Patos (Camaquã, Tapes e Canal São Gonçalo, Pelotas). O resultado na análise dos componentes principais para os caracteres morfométricos evidenciou uma sobreposição entre os grupos (Fig. 11). Os peixes da Lagoa dos Patos formaram um agrupamento em posição superior aos demais, também ocupado pelos peixes da Lagoa Mirim. Dois indivíduos da Lagoa dos Patos (OTUs 39, 40) mantiveram-se afastados dos demais, pois foram obtidos junto à Tapes (região norte da laguna). Os demais foram coletados mais ao sul da laguna, dois em Camaquã e seis no Canal São Gonçalo, Pelotas (Fig. 1). A OTU 38, coletada em Pelotas, posicionou-se afastada das demais OTUs (à direita do gráfico), devido ao seu maior tamanho ( $225 \mathrm{~mm}$ cp contra $100-122 \mathrm{~mm} \mathrm{cp}$ ). Os peixes da Lagoa Mirim, coletados no banhado do Taím, tiveram uma distribuição bem mais ampla, enquanto os indivíduos da Lagoa dos Quadros dispuseram-se próximos uns dos outros, formando um grupo mais à direita. 
O primeiro componente principal explicou $96,98 \%$ da variação total e descreveu as diferenças de tamanho. Os coeficientes do primeiro componente foram positivos e de semelhante magnitude $(0,214-0,190)$. Com exceção da variável olho $(0,125)$, todas as outras contribuíram igualmente para este fator tamanho geral, que conteve também informações sobre aspectos alométricos da forma dos peixes, observados pelos valores dos coeficientes alométricos (Tab. II). As variáveis de coeficiente mais elevado no primeiro componente foram: altcab $(0,214)$, boca $(0,212)$, ppl, cab e foc $(0,209)$, intorb e altped $(0,208)$, expressas como coeficientes alométricos positivos, enquanto a variável olho $(0,125)$, apresentou o menor coeficiente alométrico negativo (Tab. II).

Tabela II. Pesos dos componentes principais para Odontesthes mirinensis, sp.n.. Caracteres morfométricos log-transformados de 46 OTUs combinadas, extraídos da matriz de dispersão.

\begin{tabular}{|c|c|c|c|c|}
\hline Variáveis & CP1 & $C P 2$ & CP3 & Coeficiente alométrico \\
\hline Percentagem de variāncia & 96,98 & 0.560 & 0,430 & \\
\hline $\mathrm{CP}$ & 0,200 & 0.030 & 0,006 & 1.00 \\
\hline $\mathrm{pd} 2$ & 0.205 & 0.014 & 0,042 & 1.03 \\
\hline pd 1 & 0.201 & 0.067 & 0.095 & 1.01 \\
\hline pan & 0,197 & 0,073 & 0,024 & 0,99 \\
\hline $\mathrm{pp} 2$ & 0,197 & 0.082 & 0,049 & 0.99 \\
\hline $\mathrm{pp} 1$ & 0,209 & 0,172 & 0,207 & 1,05 \\
\hline$c a b$ & 0.209 & 0,175 & 0,121 & 1.05 \\
\hline altcab & 0,214 & 0.207 & 0.068 & 10,7 \\
\hline foc & 0,209 & 0,007 & 0.008 & 1,05 \\
\hline otho & 0,125 & 0,334 & -0.588 & 0,63 \\
\hline intorb & 0.208 & 0,154 & 0,130 & 1,04 \\
\hline boca & 0,212 & 0,084 & 0.103 & 1.06 \\
\hline $\max$ & 0,190 & 0,322 & 0,242 & 0,95 \\
\hline altped & 0,208 & 0,268 & 0,171 & 1,04 \\
\hline p1p2 & 0,198 & 0.015 & 0,308 & 0.99 \\
\hline$p 1 p c$ & 0,200 & 0,041 & 0.064 & 1,00 \\
\hline $\mathrm{p} 2 \mathrm{pc}$ & 0,205 & 0.061 & 0.053 & 1.03 \\
\hline anpc & 0.203 & 0,046 & 0.025 & 1,02 \\
\hline d1pc & 0.203 & 0,101 & 0.052 & 1,02 \\
\hline$d 2 p c$ & 0.193 & 0.062 & 0.054 & 0.97 \\
\hline$d 1 d 2$ & 0,198 & 0.648 & 0,314 & 0,99 \\
\hline and 1 & 0,200 & 0.023 & 0.359 & 1.00 \\
\hline and 2 & 0,201 & $-0,076$ & 0,304 & 1,01 \\
\hline anp 1 & 0,201 & 0,090 & 0,101 & 1,01 \\
\hline anp2 & 0,194 & 0,323 & 0,155 & 0,97 \\
\hline
\end{tabular}

O segundo componente principal explicou um adicional de $0,56 \%$ da variação total. Seus coeficientes representaram um contraste entre as seguintes variáveis: olho $(0,334), \max (0,322)$, altped $(0,268)$, cab $(0,175)$, versus $\mathrm{d} 1 \mathrm{~d} 2$ $(-0,648)$, anp2 $(-0,323)$, altcab $(-0,207)$, d1pc $(-0,101)$. Não foram observadas variações nas proporções corporais dos peixes, entre cabeça e região posterior. Analisando-se as médias destas proporções corporais, verificou-se que foram muito semelhantes, indicando que a espécie não apresentou variação morfológica evidente entre os locais amostrados, segundo este contraste de variáveis (Tab. III). 
Tabela III. Dados comparativos dos caracteres morfométricos de três populações de Odontesthes mirinensis, sp.n.. Medidas expressas em percentagens do comprimento padrão e comprimento da cabeça. (mín.) Limite mínimo, (máx.) limite máximo, (méd.) média, (d) desviopadrão, (CV) coeficiente de variação.

\begin{tabular}{|c|c|c|c|c|c|c|c|c|c|c|c|c|c|c|c|}
\hline & \multicolumn{5}{|c|}{ Lagoa dos Quadros $(n=7)$} & \multicolumn{5}{|c|}{ Lagoa Mirim $(n=23)$} & \multicolumn{5}{|c|}{ Lagoa dos Patos $(n=11\}$} \\
\hline & Min. & Máx & Méd. & d & $\mathrm{CV}$ & Min. & Máx & Mèd. & d & $\mathrm{CV}$ & Min. & Máx & Mèd. & d & $\mathrm{CV}$ \\
\hline $\operatorname{cp}(\mathrm{mm})$ & 129 & 164 & & & & 95 & 148 & & & & 100 & 225 & & & \\
\hline \multicolumn{16}{|c|}{ Percentagens do comprimento padrâo } \\
\hline pd 1 & 58,8 & 61.7 & 59.9 & 1,1 & 1,9 & 59.9 & 63,8 & 61,4 & 1,0 & 1,7 & 59.0 & 64,4 & 62,2 & 1,6 & 2,6 \\
\hline $\mathrm{pd} 2$ & 72,2 & 75,1 & 73,9 & 0.8 & 1.1 & 72.6 & 76.5 & 74.4 & 1.0 & 1.3 & 72.1 & 76,8 & 74,7 & 1,5 & 2.0 \\
\hline pan & 63,6 & 65.2 & 64,4 & 0.5 & 0.8 & 62.1 & 67.6 & 65.2 & 1.5 & 2,2 & 62.7 & 67,3 & 65,0 & 1.7 & 2,6 \\
\hline $\mathrm{pp} 1$ & 24,0 & 26.2 & 24.7 & 0.7 & 3.0 & 21.9 & 25.7 & 24,1 & 1.0 & 4.0 & 22,0 & 25,9 & 24,3 & 0.9 & 3,9 \\
\hline $\mathrm{pp} 2$ & 43,9 & 48,4 & 45,9 & 1,4 & 3,0 & 44,9 & 48,2 & 46,6 & 0,9 & 1.9 & 44,0 & 48,7 & 46,1 & 1,4 & 3,1 \\
\hline$c a b$ & 21,8 & 23,6 & 22,8 & 0,6 & 2,7 & 20,5 & 23,9 & 22,5 & 0,9 & 3,8 & 21,0 & 23,2 & 22,6 & 0.6 & 2.8 \\
\hline altcab & 11.4 & 13,2 & 12,6 & 0.7 & 5,2 & 11,3 & 14,3 & 12,3 & 0,7 & 5,8 & 11,8 & 13,8 & 12,5 & 0,5 & 4,1 \\
\hline foc & 6,6 & 7,6 & 6,9 & 0,4 & 5,2 & 6,3 & 7,5 & 6,8 & 0,3 & 4,6 & 6,7 & 7,6 & 7,1 & 0,3 & 3,6 \\
\hline altped & 7,9 & 8,6 & 8,3 & 0,2 & 2,6 & 6,9 & 9,1 & 8,1 & 0,5 & 6,3 & 7,6 & 9,6 & 8,3 & 0,6 & 7,0 \\
\hline p1p2 & 21,3 & 25,0 & 24,0 & 1.2 & 4,8 & 22,7 & 26,5 & 24,5 & 1.1 & 4,4 & 22.6 & 26,0 & 24,4 & 1,0 & 4,0 \\
\hline p1pc & 75,6 & 78,1 & 76,5 & 0.9 & 1,2 & 75,5 & 78,9 & 77.2 & 0,8 & 1.0 & 76,0 & 79.0 & 77.5 & 1.1 & 1,4 \\
\hline$p 2 p c$ & 55,7 & 59,6 & 57.7 & 1.2 & 2,1 & 55.5 & 58,8 & 56,8 & 0.9 & 1,5 & 56.0 & 60,1 & 58,1 & 1,4 & 2,4 \\
\hline anpc & 36,6 & 41,5 & 39,1 & 1.7 & 4,4 & 35,8 & 38,9 & 37,5 & 0,8 & 2,3 & 37.2 & 40,2 & 38,5 & 1,0 & 2,5 \\
\hline $\mathrm{d} 1 \mathrm{pc}$ & 39,0 & 41,9 & 39,9 & 1.0 & 2.4 & 36,3 & 41,0 & 39.1 & 1,2 & 3,2 & 37,8 & 40.9 & 39,4 & 1,0 & 2,5 \\
\hline$d 2 p c$ & 26,2 & 27,8 & 27,0 & 0,6 & 2,1 & 24,2 & 29,6 & 26,5 & 1,2 & 4,6 & 25.7 & 28,7 & 27,3 & 0.9 & 3,2 \\
\hline $\mathrm{d} 1 \mathrm{~d} 2$ & 13,1 & 15,7 & 13,9 & 0,9 & 6,2 & 11,3 & 15,8 & 13,1 & 1,0 & 7.7 & 11,1 & 14,2 & 12,6 & 1,0 & 7,6 \\
\hline and 1 & 17.0 & 18,6 & 17,6 & 0.6 & 3,3 & 16,5 & 19.6 & 18.4 & 0.8 & 4,4 & 16.8 & 20,0 & 18,1 & 1.2 & 6,4 \\
\hline and 2 & 19.5 & 21,3 & 20.2 & 0.6 & 2,7 & 18.9 & 22,8 & 20,8 & 1,0 & 5.0 & 19,2 & 22.3 & 20.9 & 1.0 & 4,8 \\
\hline anp1 & 39.6 & 42,8 & 41,8 & 1,2 & 2,8 & 40,2 & 44,4 & 42,7 & 1,2 & 2,7 & 39,2 & 43.6 & 41,7 & 1,4 & 3,3 \\
\hline anp2 & 17.6 & 21,5 & 19,9 & 1,1 & 5,6 & 17.4 & 22,3 & 19,9 & 1,3 & 6,3 & 17,0 & 21,3 & 19,5 & 1,4 & 7,2 \\
\hline \multicolumn{16}{|c|}{ Percentagens do comprimento da cabeça } \\
\hline foc & 29,2 & 32,0 & 30,5 & 1,0 & 3,4 & 28.1 & 32,9 & 30,4 & 1,4 & 4,5 & 30,3 & 33,3 & 31,3 & 1,0 & 3,3 \\
\hline olho & 22,4 & 27,8 & 25.2 & 2,1 & 8,3 & 23.3 & 29,2 & 26,5 & 1,8 & 6.8 & 18,2 & 29,2 & 24,7 & 3,3 & 13,3 \\
\hline intorb & 25,2 & 31,5 & 27,5 & 2,0 & 7,3 & 25,0 & 30,4 & 28,0 & 1,5 & 5.2 & 26,2 & 30,8 & 28.6 & 1.4 & 4,9 \\
\hline boca & 23,2 & 29,0 & 26.6 & 2,1 & 7.8 & 22.8 & 29,2 & 25.0 & 1.6 & 6,3 & 23,5 & 28.8 & 25,6 & 1.5 & 5.8 \\
\hline $\max$ & 31.0 & 35,0 & 32.7 & 1,6 & 4,9 & 29.6 & 35.9 & 33.2 & 1.8 & 5,3 & 30.4 & 35.2 & 33,6 & 1.3 & 3,9 \\
\hline
\end{tabular}

O resultado na análise dos componentes principais para os caracteres merísticos permitiu visualizar uma distribuição com bastante sobreposição entre os espécimens (Fig. 12).

Os indivíduos da Lagoa dos Patos, obtidos junto à Camaquã e Tapes (norte da laguna), formaram o agrupamento mais superior do gráfico de dispersão, enquanto o restante do grupo, coletado no Canal São Gonçalo, Pelotas (sul da laguna), esteve espalhado entre os demais espécimens. A ligação entre a Lagoa Mirim e a Lagoa dos Patos, através do Canal São Gonçalo, permite considerar que indivíduos coletados nesses dois ambientes formem um único agrupamento, levando a crer que a espécie é recente, não tendo se diferenciado em populações. Os peixes da Lagoa dos Quadros estiveram distribuídos por entre os demais espécimens.

Os três primeiros componentes principais explicaram $67,88 \%$ da variação total presente na matriz de correlação. O primeiro componente foi responsável por $32,49 \%$ da variação total. Os caracteres que melhor refletiram esta distribuição

Revta bras. Zool. 12 (4): $881-903,1995$ 
tiveram os seguintes coeficientes: espd $1(-0,846)$, brqi $(0,835)$, brqt $(0,789)$, eslong $(-0,642), \mathrm{d} 2(0,623)$. O segundo componente explicou $19,84 \%$ da variação com os seguintes coeficientes: d1 $(-0,674)$, an $(-0,641)$, esped $(-0,486)$, eslong $(0,474)$, brqi $(0,436)$. A análise dos componentes principais permitiu visualizar a proximidade entre os agrupamentos da Lagoa Mirim e Lagoa dos Patos, principalmente daqueles indivíduos coletados no Canal São Gonçalo, em Pelotas. Os peixes da Lagoa Mangueira estiveram mais afastados dos demais, provavelmente pelo baixo número amostral $(\mathrm{n}=3)$.

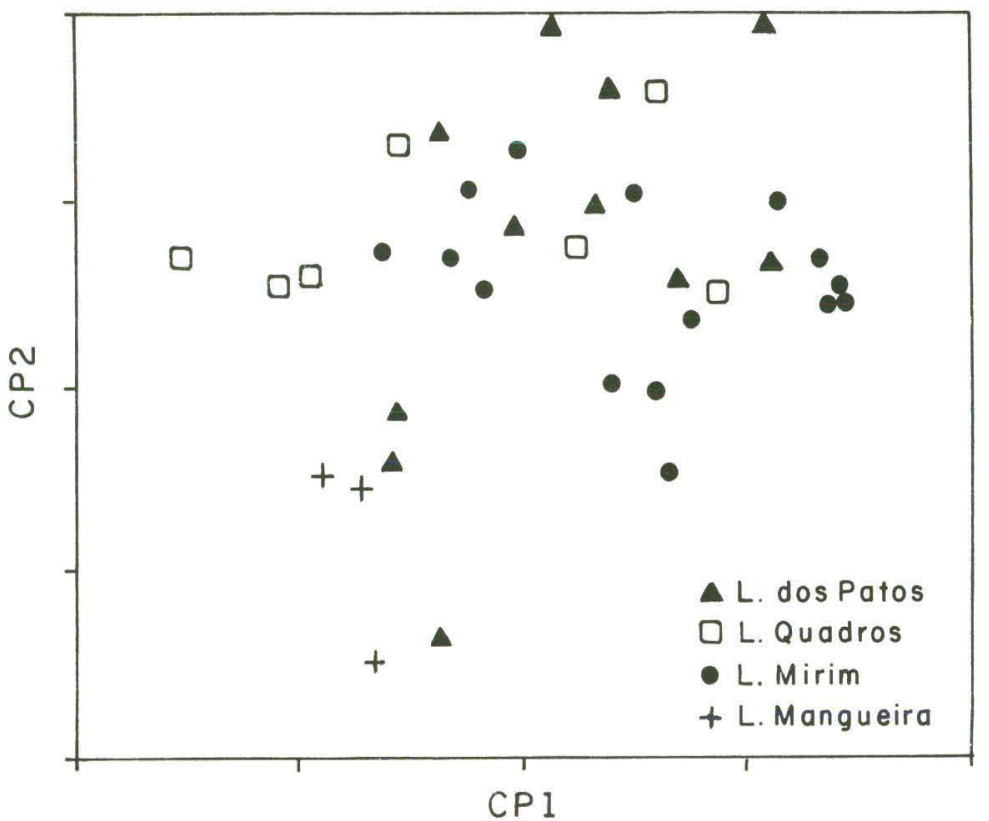

Fig. 12. Análise dos componentes principais das 37 OTUs combinadas de Odontesthes mirinensis, sp.n.; projeção dos escores individuais no espaço dos dois primeiros componentes (CP1, CP2), para nove caracteres merísticos (d1, d2, an, and2, eslong, espd1, esped, brqi, brqt).

AGRADECIMENTOS. Agradeço o apoio de Morevy Moreira Chesse do Museu Carlos Ritter de Pelotas, pelo auxílio na coleta dos exemplares no Canal São Gonçalo. Ao oceanólogo André Gonçalves pelo auxílio em algumas ilustrações e ao desenhista Brasílio Lourenço pelo acabamento final dos gráficos.

\section{REFERÊNCIAS BIBLIOGRÁFICAS}

AleXANDER, R.M.M. 1967. Mechanisms of the jaws of some atheriniform fish. J. Zool. Lond. 151: 233-255.

BEMVENUTI, M. DE A. 1993. Redescrição do peixe-rei Odontesthes argentinensis (Valenciennes) Pisces: Atherinidae, na costa do Rio Grande do Sul. Atlântica, 
Rio Grande, 15: 17-35.

1995. Análise Fenética de espécies de Odontesthes (Pisces: Atherinidae, Atherinopsinae) do extremo sul do Brasil. Tese de Doutorado, não publicada, Universidade Federal do Paraná, 201p.

_. (no prelo). Análise das relações morfológicas e osteológicas das espécies Odontesthes perugiae e Odontesthes mirinensis. Atlântica, Rio Grande.

Bookstein, F.; B. Chernoff; R. Elder; J. Humphries; G. Smith; R. Strauss. 1985. Morphometrics in evolutionary biology. Acad. Nat. Sci. Philad. (Spec. Publ.) (15): 1-277.

Cavalcanti, M.J. \& P.R.D. Lopes. 1990. Morfometria comparada de Ctenosciaena gracilicirrhus, Paralonchurus brasiliensis e Micropogonias furnieri (Teleostei: Sciaenidae) pela análise multivariada de redes de treliças. Revta bras. Zool. 7 (4): 627-635.

Chernoff, B. 1986. Phylogenetic relationships and reclassification of Menidiinae silverside fishes with emphasis of the Membradini. Proc. Acad. Nat. Sci. Philad. 138 (1): 189-249

DYER, B. 1994. Phylogenetic Systematics of the South American Silverside Genus Odontesthes Evermann \& Kendall, 1906 (Teleostei, Atheriniformes, Atherinopsinae). PhD. Thesis, not publicated, University of Michigan.

Evermann, B.W. \& W.C. Kendall. 1906. Notes on a collections of fishes from Argentina, South America, with descriptions of three new species. Proc. U.S. nat. Mus. 31 (1482): 67-108.

Fialho, C.B. \& J.R.Verani. 1994. Dinâmica da alimentação de Odontesthes aff. perugiae (Evermann \& Kendall, 1906) da Lagoa Emboada, RS, Brasil. (Atheriniformes, Atherinidae). Comun. Mus. Ciênc. Tecnol. PUCRS, Sér. Zool., Porto Alegre, 7: 29-40.

Jolicoeur, P. 1963. The multivariate generalization of the allometry equation. Biometrics 19: 497-499.

NEFF, N.A. \& L.F. MARCUS. 1980. A survey of multivariate methods for systematics. New York, Privately published.

NurSalL. J.R. 1963. The hypurapophysis, an imortant element of the caudal skeleton. Copeia 1963 (2): 458-459.

PotthofF, T. 1983. Clearing and staining Techniques, p.35-47. In: H.G. Moser, W.J. Richards, D.M. Cohen, M.P. Fahay, A.W. Kendall JR. \& S.L. RICHARDSON. (Eds). Ontogeny and systematics of fishes. Amer. Soc. Ichthyol. Herpetol, Special Publication 1, 760p.

RAuCHEMBERGER, M. 1988. A new species of Allodontichthys (Cyprinodontiformes: Goodeidae), with comparative morphometrics for the genus. Copeia (2): 433-441.

REIS, S.F. dos 1988. Morfometria e estatistica multivariada em biologia evolutiva. Revta bras. Zool. 5 (4): 571-580.

ROHLF, F.J. 1989. NTSYS-pc. Numerical taxonomy and and multivariate analysis system. Version 1.50. New York, Department of Ecology Evolution, Stony Brook, 37p. 
ROJO, A.L. 1991. Dictionary of evolutionary fish osteology. CRC Press, Florida $273 p$.

Rosen, D.E. 1964. The relationships and taxonomic position os the halfbeaks, killifishes, silversides and their relatives. Bull. Amer. Mus. Nat. Hist. 127 (5): $219-267$.

SEAL, H.L. 1964. Multivariate statistical analysis for biologists. London, Methuen, 209p.

SOKal, R.R. \& F.J. RohlF. 1981. Biometry. San Francisco, W.H. Freeman, $2^{\text {nd }}$ ed., $859 \mathrm{p}$.

STRAuSS, R.E. 1985. Evolutionary allometry and variation in body form in the South American Catfish genus Corydoras (Callichthydae). Syst. Zool.,34 (4): 381-396.

TAYLOR, W.R. 1967. An enzyme method of clearing and staining small vertebrates. Proc. U.S. nat. Mus. 122 (3596): 1-17.

White, B.N. 1985. Evolutionary relationships of the Atherinopsinae (Pisces: Atherinidae). Contrib. Scien. 368: 1-20.

WINAMS, G.A. 1987. Using morphometric and meristic characters for identifying stocks of fish. NOAA Techniques Memorandum 199: 25-62. 